\title{
'Det er easy at tale engelsk også'. American Danish in the 1960s and 1970s
}

\section{KAROLINE KÜHL}

The conditions for the Danish language among Danish emigrants and their descendants in the United States in the first half of the 20th century were tough: The group of Danish speakers was relatively small, the Danes did not settle together as other immigrant groups did, and demographic circumstances led many young, unmarried Danish men to marry non-Danish speaking partners. These were all factors that prevented the formation of tight-knit Danish-speaking communities. Furthermore, US nationalistic propaganda in the wake of World War I and the melting-pot effect of post-war American society in the 1950s contributed to a rapid decline in the use of Danish among the emigrants. Analyses of recordings of 58 Danish-American speakers from the 1970s show, however, that the language did not decline in an unsystematic process of language loss, only to be replaced quickly and effectively by English. On the contrary, the recordings show contactinduced linguistic innovations in the Danish of the interviewees, which involve the creation of specific lexical and syntactical American Danish features that systematically differ from Continental Danish. The article describes and discusses these features, and gives a thorough account of the socioeconomic and linguistic conditions for this speaker group. 